\title{
Erratum zu: Photorefraktive Keratektomie in Kombination mit Hornhautquervernetzung - eine Alternative zur Keratoplastik bei Keratokonus?
}

Filip Filev · Jenny Borissova · Robert Kromer - Daniela Mitova

Online publiziert: 13. April 2017

(C) Springer-Verlag Wien 2017

\section{Erratum zu:}

\section{Spektrum Augenheilkd}

DOI 10.1007/s00717-017-0336-y

Leider enthielt dieser Beitrag bei Manuskripteinreichung einen falsch geschriebenen Namen, Jeny Boriskova, der Co-Autorin. Korrekt lautet der Name Jenny Borissova.

Interessenkonflikt F. Filev, J. Borissova, R. Kromer und D. Mitova geben an, dass kein Interessenkonflikt besteht. 